\title{
Glioma-associated Peptide-loaded Dendritic Cell Vaccine SL-701
}

National Cancer Institute

\section{Source}

National Cancer Institute. Glioma-associated Peptide-loaded Dendritic Cell Vaccine SL-

701. NCI Thesaurus. Code C114496.

A cell-based cancer vaccine comprised of dendritic cells (DCs) pulsed with various,

synthetic glioma-associated antigen (GAA) peptides, with potential antineoplastic activity. Upon subcutaneous administration, the glioma-associated peptide-loaded DC vaccine SL701 exposes the immune system to various GAA peptides. This may stimulate both antitumoral cytotoxic T lymphocyte (CTL) and antibody responses against the GAAexpressing glioma cells, which may result in tumor cell lysis. 